\title{
Investigations of acute toxicity and neurotoxin effects of aqueous extracted pyrethroid (deltamethrin) from insecticide treated mosquito net on clarias gariepinus and heterobranchus bidorsalis
}

\begin{abstract}
There is dearth of literature on effects of aqueous extracted deltamethrin from Long-lasting Insecticide-treated Nets (LLINs) on fish. In malaria endemic regions LLINs are distributed free as governments' efforts to control malaria. These mosquito nets are converted into fishing nets by fishermen. The aim of this study was to determine the effects of Aqueous Extracted Deltamethrin AED on Clarias gariepinus and Heterobranchus bidorsalis. Larva, fry and fingerlings stages of experimental fish species total 720 were exposed to 0,50 , $100,150,200$, and 250ppt of AED for 24, 48, 72, and 96 hours. Guide for the care and use of experimental fish was followed. Data was analysed using ANOVA. 100\% mortality was observed at 250ppt from both species at all stages in 48-96hours. Lowest lethal concentration LC was 50ppt for larva and fry stages of both species at 72 hours, and 100ppt at 96 hours for fingerlings in both species. Larva and fry were most affected. There was no significance difference $(\mathrm{P}>0.05)$ in the effects of AED on both species. The practice of using LLINs for fishing should be discouraged. This negatively affects fish, aquatic biodiversity, and the environment.
\end{abstract}

Keywords: fish, lethal, toxicology, malaria, mortality, insecticide, aquatic biodiversity, clarias gariepinus, heterobranchus bidorsalis
Volume I Issue 4 - 2017

\author{
Lord Tertese Angahar \\ Department of Biological Sciences, Federal University of \\ Agriculture, Nigeria
}

\begin{abstract}
Correspondence: Lord Tertese Angahar, Department of Biological Sciences, Federal University of Agriculture P.M.B 2373 Makurdi, Nigeria, Email lordlegs365@gmail.com
\end{abstract}

Received: June 21, 2017 | Published: July 10, 2017

\section{Introduction}

Pyrethroids (also known as synthetic Pyrethroids) are insecticides chemically similar to pyrethrins found in pyrethrum extracted from the flower of chrysanthemum, known for centuries for their insecticidal activity. ${ }^{1}$ They are used as pesticides in homes and for agricultural purpose. Pyrethroids are historically divided into two types, according to their chemical structure. Type I (First generation) pyrethroids, do not contain an $\alpha$-cyano group in the molecule (for example, allethrin, resmehrin, D-phenothrin, and permethrin), and causes mainly tremors (T-syndrome). ${ }^{2}$ Type II (Second generation) pyrethroids contain an $\alpha$-cyano group (for example, deltamethrin, cypermethrin, cyfluthrin, $\gamma$-cyhalothrin and fervalerate. These groups cause choreoathetosis and salivation (CS-syndrome). ${ }^{2}$ They also cause paresthesia, which is characterised by transient burning/tingling/itching sensation of the exposed skin. ${ }^{3}$ The first generation pyrethroids are less toxic to mammals than the second generation. ${ }^{3}$ Deltamethrin products are among the most popular and widely used insecticides in the world. Deltamethrin was synthesized in 1974, and first marketed in $1977 .{ }^{4}$ The chemical formula of deltamethrin is $\mathrm{C}_{22} \mathrm{H}_{10} \mathrm{Br}_{2} \mathrm{NO}_{3}$. It is used extensively in agriculture for controlling pest, insects and vectors of endemic diseases, protecting seeds during storage and fighting household insects because of their low environmental persistence. ${ }^{5}$ Deltamethrin is composed of eight stereometric esters (four cis and four trans isomers) of the di-bromo analogue of chrysanthemic acid, 2, 2-dimethyle-3 cyclopropanecarboxylic acid. ${ }^{4}$ It is prepared by the esterification of (1R,3R)-or cis2, 2-dimethyl-3 (2,2, dibromovinyl) cyclopropanecarboxylic with (alpha, s)-or (+)-alpha-cyano-3phenoxybenzyle alcohol or by selective recrystallization of the racemic esters obtained by esterification of the $(1 \mathrm{R}, 3 \mathrm{R})$-or cis-acid with racemic or (alpha-R, alpha-s, or alpha-R/S)-or + or - alcohol. Deltamethrin is used in the production of Long-lasing Insecticidetreated Nets (LLINs). They have become particularly very prevalent in malaria endemic countries like Nigeria, and are regarded as an important tool in the "Roll Back malaria Campaign". Thus, it plays a key role in the control of malaria vectors (mosquitos). Deltamethrin is a neurotoxin, and temporary attacks the nervous system of any animal it comes in contact, including human. It cause tingling or reddening of the skin, and has been reported to be responsible for allergen and asthma in some people. ${ }^{6}$ There was wide-spread repots of isolated fatal incidence associated with the use of LLINs between 2014-2015 in Nigeria. In South Africa, deltamethrin was isolated from breast milk, believed to get in through the skin. ${ }^{7}$ It is however, generally, considered safe to use around human. ${ }^{6}$ Reports of acute deltamethrinhuman poisoning, other than from occupational exposure, are rare. ${ }^{6}$ The world Health Organization classified it as 'moderately hazardous' ${ }^{8}$ Nevertheless, deltamethrin is very toxic to aquatic organisms. Deltamethrin and other Pyrethroids have been found to be extremely toxic to fish., ${ }^{9,10}$ There are several reports on the induced toxic effects of deltamethrin in different fish. ${ }^{11}$

It has been observed that, because LLINs are distributed freely, local residents sometimes easily use them inappropriately; as fishing nets and for construction of passive fishing gears (traps). ${ }^{12-14}$ Studies on the effects of deltamethrin on fish abound, and well documented. ${ }^{15-17}$ Most of the studies used deltamethrin products, particularly pesticides. There is no study on aqueous extracted deltamethrin (AED) from Long-lasting Insecticide-treated Net on members of 
the family clariidae. Apart from agricultural sources, large volumes of deltamethrin which escaped into the aquatic environment in SubSaharan Africa come from the use of LLINs for fishing. The aim of this study is to determine the effects of aqueous extracted deltamethrin on Claris gariepinus (Burchell, 1822) and Heterobranchus bidorsalis (Geoffory Saint-Hilaire, 1809). The study objectives are: To protect and conserve fish, and other aquatic organisms from the neurotoxicity of pyrethroids (deltamethrin), to discourage the use of LLINs for fishing, thus sustaining efforts to control malaria.

\section{Materials and methods}

\section{Test organisms}

360 Clarias gariepinus and 360 Heterobranchus bidorsalis fish seeds used for the study. They were obtained from a standard fish hatchery. The fish seeds where of same age from each group (larva, fry and fingerlings). The fish were used in accordance with the Canadian guidelines on the care and use of fish in research, teaching and testing ${ }^{18}$ and National Research Council guide for the care and use of laboratory animals. ${ }^{19}$

\section{Aqueous extraction of deltamethrin from LLINs}

Three new LLINs with a trade name Dawaplus 2.0 freely distributed under the auspices of the US president malaria initiative, produced by Tana nettings in Pakistan were used for the extraction. The nets were exposed to air, free from sunlight and rain for 21days, prior to extraction. The nets were then soaked in a plastic bowel with 15 litres of clean water. The physicochemical parameters of the water were: $6 \mathrm{mg} / 1,26^{\circ} \mathrm{c}$ and $215 \mathrm{mg} / 1$ for dissolved oxygen, temperature, $\mathrm{pH}$ and total hardness respectively. The nets were left soaked in the water for 3 hours after which, they were removed, gently squeezed, and airdried. The aqueous extracted deltamethrin (AED) was turned into a clean gallon and covered for use.

\section{Experimental design}

The experiment consisted of six treatments. Treatment I (0ppt), Treatment II (50ppt), Treatment III (100ppt), Treatment VI (150ppt), Treatment V (200ppt), and Treatment VI (250ppt). Duplicated for $C$. gariepinus and $H$. bidorsalis and replicated in pairs. Thus, total replicates were 72 . Total number of test organism used was 720,10 per each replicate.

\section{Exposure of test organisms to AED}

Water with the same physicochemical parameters $6 \mathrm{mg} / 1,26^{\circ} \mathrm{c}$ and $215 \mathrm{mg} / 1$ for dissolved oxygen, temperature, $\mathrm{pH}$ and total hardness respectively, was introduced into 72 plastic bowls. AED was then added to the bowls to obtain a concentration of $0 \mathrm{ppt}, 50 \mathrm{ppt}, 100 \mathrm{ppt}$, $150 \mathrm{ppt}, 200 \mathrm{ppt}$, and 250ppt. Thus every set of 12 bowels had the same AED concentration. Ten test organisms were introduced in every bowel. Observations were noted and mortality was recorded at 24, 48, 72 , and 96 hours of exposure.

\section{Data analysis}

Mortality rate (\%) was calculated using the expression:

Mortality rate $(\%)=\underline{\text { No of dead fish }} \times 100$ No of fish exposed to AED

Experimental data was subjected to Analysis of Variance at $95 \%$ confidence level.

\section{Results}

$100 \%$ mortality was observed at $250 \mathrm{ppt}$ from both species at all stages in 48-96 hours. Lowest lethal concentration LC was 50ppt for larva and fry stages of both species at 72 hours, and 100ppt at 96 hours for fingerlings in both species. Larva and fry were most affected. Mortality of larvae and fry started within 3 hours of exposure at $250 \mathrm{ppt}$. There was no significance difference $(\mathrm{P}<0.05)$ in the effects of AED on both species. The mortality rate of $C$. gariepinus and $H$. bidorsalis at 0ppt, 50ppt, 100ppt, 150ppt, 200ppt, and 250ppt exposed to AED for 24, 48, 72, and 96 hours is presented in (Table 1-4) shows that the behavioural pattern of the studied species exposed to AED at 96 hours was the same.

Table I Mortality rates of C. gariepinus at different conc. (ppt) of AED at 24, 48,72 and 96 hours exposure

\begin{tabular}{|c|c|c|c|c|c|}
\hline & & $24 \mathrm{hrs}$ & $48 \mathrm{hrs}$ & $72 \mathrm{hrs}$ & $96 \mathrm{hrs}$ \\
\hline Dev. stage & Conc.(ppt) & \multicolumn{4}{|c|}{ Mortality rate (\%) } \\
\hline \multirow[t]{6}{*}{ Larvae } & 0 & 0 & 0 & 0 & 0 \\
\hline & 50 & 0 & 0 & 10 & 30 \\
\hline & 100 & 10 & 20 & 20 & 40 \\
\hline & 150 & 30 & 40 & 60 & 80 \\
\hline & 200 & 40 & 60 & 80 & 100 \\
\hline & 250 & 80 & 100 & 100 & 100 \\
\hline \multirow[t]{6}{*}{ Fry } & 0 & 0 & 0 & 0 & 0 \\
\hline & 50 & 0 & 0 & 10 & 10 \\
\hline & 100 & 0 & 10 & 10 & 20 \\
\hline & 150 & 20 & 30 & 50 & 60 \\
\hline & 200 & 30 & 40 & 80 & 100 \\
\hline & 250 & 40 & 100 & 100 & 100 \\
\hline \multirow[t]{6}{*}{ Fingerlings } & 0 & 0 & 0 & 0 & 0 \\
\hline & 50 & 0 & 0 & 0 & 0 \\
\hline & 100 & 0 & 0 & 0 & 10 \\
\hline & 150 & 10 & 20 & 30 & 50 \\
\hline & 200 & 20 & 30 & 60 & 80 \\
\hline & 250 & 60 & 100 & 100 & 100 \\
\hline
\end{tabular}

Table 2 Mortality rates of $H$. bidorsalis at different conc. (ppt) of AED at 24, 48,72 and 96 hours exposure

\begin{tabular}{llllll}
\hline & & $24 \mathbf{h r s}$ & $\mathbf{4 8 h r s}$ & $\mathbf{7 2 h r s}$ & $\mathbf{9 6 h r s}$ \\
\hline Dev. stage & Conc.(ppt) & \multicolumn{2}{l}{ Mortality rate (\%) } \\
\hline Larvae & 0 & 0 & 0 & 0 & 0 \\
& 50 & 0 & 10 & 20 & 30 \\
& 100 & 10 & 30 & 40 & 40 \\
& 150 & 30 & 50 & 60 & 80 \\
& 200 & 50 & 80 & 100 & 100 \\
& 250 & 90 & 100 & 100 & 100 \\
\hline
\end{tabular}


Table Continued....

\begin{tabular}{|c|c|c|c|c|c|}
\hline & & $24 \mathrm{hrs}$ & $48 \mathrm{hrs}$ & $72 \mathrm{hrs}$ & 96hrs \\
\hline Dev. stage & Conc.(ppt) & \multicolumn{4}{|c|}{ Mortality rate (\%) } \\
\hline \multirow[t]{6}{*}{ Fry } & 0 & 0 & 0 & 0 & 0 \\
\hline & 50 & 0 & 10 & 10 & 20 \\
\hline & 100 & 10 & 20 & 20 & 30 \\
\hline & 150 & 20 & 30 & 60 & 60 \\
\hline & 200 & 40 & 50 & 80 & 100 \\
\hline & 250 & 50 & 100 & 100 & 100 \\
\hline \multirow[t]{6}{*}{ Fingerlings } & 0 & 0 & 0 & 0 & 0 \\
\hline & 50 & 0 & 0 & 0 & 0 \\
\hline & 100 & 0 & 0 & 10 & 10 \\
\hline & 150 & 10 & 30 & 40 & 60 \\
\hline & 200 & 30 & 40 & 70 & 90 \\
\hline & 250 & 70 & 100 & 100 & 100 \\
\hline
\end{tabular}

Table 3 Behavioural pattern of $C$. gariepinus exposed to AED for 96 hours

\begin{tabular}{|c|c|c|c|}
\hline Behaviour & Larvae & Fry & Fingerlings \\
\hline Opercula movement increased & - & - & ++ \\
\hline Loss of equilibrium & + & ++ & ++ \\
\hline Erratic swimming & ++ & ++ & +++ \\
\hline Sudden swimming follow by interruption & - & ++ & ++ \\
\hline Circular swimming & +++ & ++ & + \\
\hline Loss of colour & + & + & + \\
\hline
\end{tabular}

Table 4 Behavioural pattern of $H$. bidorsalis exposed to AED for 96 hours

\begin{tabular}{llll}
\hline Behaviour & Larvae & Fry & Fingerlings \\
\hline Opercula movement increased & - & - & +++ \\
Loss of equilibrium & + & ++ & ++ \\
Erratic swimming & + & + & ++ \\
Sudden swimming follow by interruption & - & ++ & ++ \\
Circular swimming & ++ & ++ & + \\
Loss of colour & + & + & +
\end{tabular}

\section{Discussion}

Deltamethrin is very toxic to fish as observed because fish is reported to be deficient in enzymes that hydrolyze deltamethrin. Thus, fish have relatively slow metabolism and slow elimination of these compounds. ${ }^{20}$ Also due to their lipophilicity, Pyrethroids have a high rate of gill absorption..$^{21}$ This explains the strong sensitivity of fish to AED exposures. Acute toxicity and neurotoxic effects of deltamethrin was higher in fish larvae and fry than fingerlings. Getlemanian, ${ }^{12}$ also observed that pyrethroids are more toxic to smaller fish than larger ones. Moore and Waring, ${ }^{22}$ reported that sub-lethal pyrethroids exposures altered a number of reproductive and early developmental processes in fish.
The experimental organisms exhibited erratic movement, loss of balance, respiratory distress, operculum open and closes at quick succession. De Micco et al. ${ }^{23}$ reported that low levels of pyrethroids because neurobehavioral affects in young zebra fish Danio rerio. Deltamethrin usually attacks the nervous system of any animal with which it comes into contact. The neurotoxic effects of synthetic pyrethroids (deltamethrin ) is attributed to the blocking of sodium channels and inhibiting the gamma-aminobutyric acid (GABA) receptors in the nervous filament which results in an excessive stimulation of the central nervous system that something can lead to brain hypoxia. ${ }^{24}$ Deltamethrin is most toxic to fish. It negatively affects aquatic organisms of biological importance. ${ }^{25}$

\section{Conclusion}

Neurotoxin effect of aqueous extracted deltamethrin on $C$. gariepinus and $H$. bidorsalis was demonstrated. Acute toxicity of deltamethrin was observed at the lava, fry and fingerling stages of the experimental fish species. Deltamethrin is highly toxic to fish at all ages. But it affects younger fish much rapidly. Artisanal fishermen and local residents should stop using LLINs meant for the control of malaria for fishing or other purpose. This negatively affects fish, aquatic biodiversity and constitutes environmental risk.

\section{Acknowledgements}

None.

\section{Conflict of interest}

The author declares no conflict of interest.

\section{References}

1. CPCN. Compendium of pesticide common name pyrethroid insecticed; 2001. p. 42-45.

2. Tordir WF, Maroni M, He F. Health Surveillance of pesticide workers. $A$ manual for occupational health professional. 1994;(91):12-15.

3. Rehman H, Aziz, T Saggu S, et al. Systematic Review of Pyrethroids toxicity with species reference to deltamethrin. Journal of entomology and Zoology studies. 2014;2(6):60-70.

4. Pham HC, Dalmasure N, Clavel C, et al. Toxicological studies of deltamethrin. Int J Tissue React. 1984;6(1):127-133.

5. Braguini WL, Cadene SM, Carnier EG, et al. Effects of Deltamethrin on functions of rat liver mitochondria and on native and synthetic model members. Toxico Lett. 2004;152(22):191-202.

6. Cockroach control; 2016.

7. Bouwman B, Sereda, Meinhardt HB. Simultaneous presence of DDT and pyrethroids residue in human breast milk from malaria endemic area in South Africa. Environ Pollut. 2006;144 (3):902-917.

8. Pan-AP, Pan APA. Factsheet series: Pyrethroids in Bed Net: Deltamethrin, etofenprox, lambda-cyhalothrin, permethrin, piperonylbutoxial pesticide action Network, Asia and the Pacific, Malaysia: 2012. p. 61-65.

9. Balint T, Szegleles T, Szegleles ZS, et al. J Biochemical and Subcellular Changes in Carp exposed to the Organophosphorous methidation and pyrethroids deltamethrin. Aquat Toxicol. 1995;33(3-4):279-295.

10. Viran R, Erkoc EU, Polat H, et al. Investigations of acute toxicity of deltamethrin on guppies (Poecilia reficulata). Ecotoxicol Environ Sat. 2003;55(1):82-85.

11. Khuli MS, Khalegi R, Hedayati. Acute toxicity test of two pesticide diazinon and deltamethrin on swordtail fish (Xiphophorrus hellerii). Global vet. 2011;2(8):541-545. 
12. Getlemanian J. Meant to keep mosquitos out. Nets are used to haul fish The New york Times: 2015. P. 9-10

13. Klep GE. Unforeseen misuse of bed nets in fishing villages along Lake Victoria. Malaria Journal. 2014;4(4):88-96.

14. IRIN Africa- AMBIA. Mosquito net fishing threatens lake Tanganyikaeconomy-food security - water and sanitation IRIN News 13; 2015.

15. Sayeed IS, Parvez S, Pandey B, et al. Oxidative Stress biomarkers of exposure to deltamethrin in fresh water fish, Channa punctatus (bloch). Ecotoxicol. Environ saf. 2003;56(2):295-301

16. Dalta M, Kaviraji A. Acute toxicity of the synthetic pyrethroids deltamethrin to fresh water catfish Clarias gariepinus. Bull Environ contam Toxical. 2011;70(2):296-299.

17. Delistraty D. Acute toxicity to rats and trout with a focus on inhalation and aquatic exposures. Ecotoxicol Environ Saf. 2000;46(2):225-233.

18. The Canadian council on animal care. Guidelines on: the care and use of fish in research, Teaching and testing. Canada: Springer; 2005. p. 233-237.

19. Institute for laboratory animal research. Guide for the care and use of laboratory Animal. Washington, USA: National Academy press; 2011
20. David M, Shivakumar HB, Shivakumar R, et al. Toxicity evaluation of Cypermethrin and Its effects on oxygen consumption of fresh water fish, tilapia Mossambicus. Indian Jenviron Toxicol. 2003;13(6):99-102.

21. Haya K. Toxicity of Pyrethroids to fish. Environ Toxicol Chem 1989;8(1):381-391.

22. Moor A, Waring CP. The effects of a synthetic pyrethroids pesticide on some aspects of reproduction in Atlantic salmon (Salmo salar L.). Aquatic toxicology. 2001;52(1):1-12.

23. Demico A, Cooper KR, Richardson JR, et al. Developmental neurotoxicity of pyrethroids insecticide in Zebra fish embryos. Toxicological Sciences. 2010;13(4):177-186.

24. El-sayed YS, Saad TT, El-bahr SM. Acute intoxication of deltamethrin in monosex Nile tilapia, Oreochromis niloticus with special reference to the clinical, biochemical and haematological effects. Environ Toxicol Pharmacol. 2007;24(3):212-217.

25. Dunca DB. Multiple range and Multiple F- test Biometric. 1995;11(1):142 